Historic, Archive Document

Do not assume content reflects current scientific knowledge, policies, or practices. 

62.29

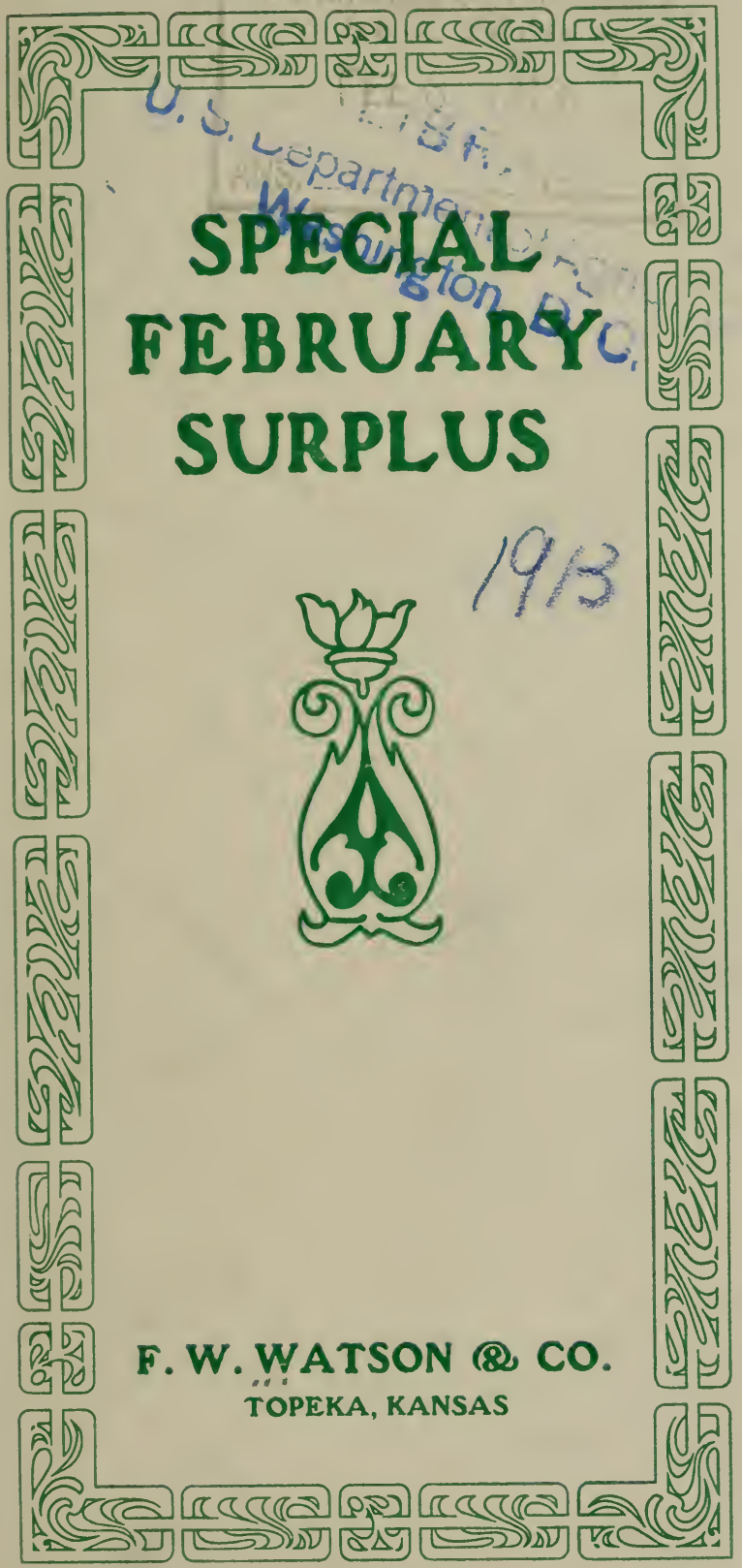




\section{SPECIAL FEBRUARY SURPLUS}

\section{F. W. WATSON \& CO. \\ TOPEKA, KANSAS}

The following stock is in our warehouse and can be shipped promptly, or held until spring, as patrons may desire. In order to close out stock quickly we have made prices very low. The most of our No. 1 Apple Seedlings were sold this season at $\$ 4.00$ per M., and were good value at that price, but we have a few No. 1 and quite a lot of No. 2 and budders on hand and make these special prices to close them out.

\section{Apple Seedlings}

130,000 Apple Seedlings, No. 1, 3-16 in. and all up, straight roots, boxed..... Per M. $\$$. 22,000 Apple Seedlings, extra, 1/4 inch and all up, branched roots, boxed . . . . 3.50 200,000 Apple Seedlings, No. 1, 3-16 in. and all up, branched roots, boxed..... 3.00

38,000 Apple Seedlings, medium, $3-16$ to $1 / 4$ in, straight roots, boxed. . . . . . 1.75 600,000 No. 2, strong grade, $21 / 2$ to $31 / 2-16$, straight, roots, boxed......... 1.00

35,000 No. 2 , strong grade, $21 / 2$ to $31 / 2-16$, branched roots, boxed . . . . . . . 1.25 120,000 Apple Seedlings, No. 3, 2-16 in., boxed . .................. .50 700,000 Apple Seedlings, special grade, 3-16 in. and up, short St. and Br..... 1.15 $\mathbf{5 0 , 0 0 0}$ or more at $\$ 1.00$ per 1,000 .

(This sp cial grade is fine for budders-straight collars.)

Above seedlings were grown by us this past season-no cold storage, contract or shipped-in stocks. They were late dug, are well matured and free from all diseases. You cannot buy better at any price.

\section{Pear Seedlings}

Per M.

40,000 Japan Pear Seedlings, No. 1, 3-16 in. and all up, St. and Br........ \$4.50

12,000 Japan Pear Seedlings, 3-16 in. and all up, branched roots......... . 5.50

5,000 Japan Pear Seedlings, No. 2, 2-16 to $3-16$ in................. 4.00

3,000 Japan Pear Seedlings, No. 3, $2-16$ in. . . . . . . . . . . . . . 2.50

3,500 Japan Pear Seedlings, No. 4, under $2-16$ in. . . . . . . . . . . . 1.50

38,000 French Pear Seedlings, No. 1, 3-16 in. and all up............. 4.00

24,000 French Pear Seedlings, No. 2, 2-16 to $3-16$ in. .............. 3.50

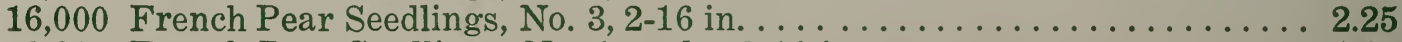

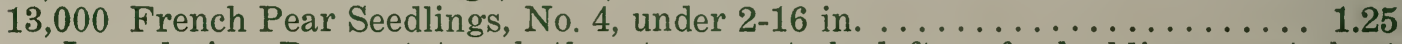

In ordering Pear, state whether tops are to be left on for budding or cut short for grafting. 


\section{Apple Grafts}

(Terms: One-fourth of amount when order is placed.)

Per M.

No. 1 Grafts, 5 to 6 inch cion, 4 to $41 \frac{2}{2}$ inch roots .................. $\$ 4.00$

In lots of 10,000 and up.... $\$ 3.50 \quad 50,000$ and up .......... 3.00

No. 1 Whole Root Grafts.................................. 5.00

In lots of 10,000 and up.... $\$ 4.00 \quad 50,000$ and up .......... 3.50

We use only 3-16 in. and up roots, wrapped with waxed thread, boxed free. All Grafts are tied 100 in a bunch. We can ship the following sorts promptly:

$\begin{array}{lllll}\text { Gano } & \text { Jonathan } & \text { Wolf River } & \text { N. W. Greening } & \text { G. Golden } \\ \text { Winesap } & \text { Mo. Pippin } & \text { Ben Davis } & \text { Lawver } & \text { Florence } \\ \text { Romanstem } & \text { Spitzenberg } & \text { Ingram } & \text { Duchess } & \text { M. B. Twig } \\ \text { Wealthy } & \text { Talman's Sweet } & \text { M. Blush } & \text { Rome Beauty } & \text { N. Spy } \\ \text { Whitney } & \text { Hyslop } & \text { Transcendent } & \text { Hubbardston } & \end{array}$

\section{Apple and Pear Seedlings for Season 1913-14}

\section{When Ready to Place Your Order Remember-}

I The growing of Apple Seedlings is our business.

פ We have warehouses devoted exclusively to the handling of Seedlings.

פ We plant five tons of apple seed every year.

g We furnish many of the largest users every year. q No order too large or too small.

q We sold several orders this season of 1,000,000 Apple Seedlings.

q We have selected some ideal land for next season's planting.

I We can serve customers better than those who make the growing of Apple Seedlings a side line. 



\section{Apple Trees, 2 Years}

The following Apple are all two-year, well grown, well graded. They have good top and root system and are free from diseases.

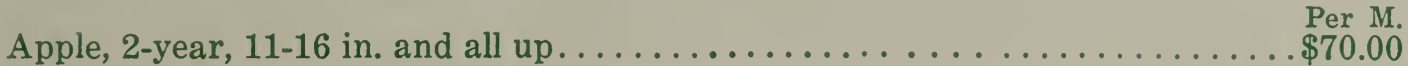

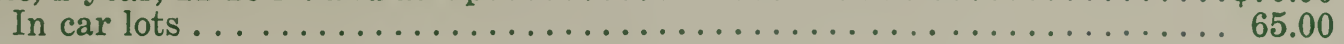

Apple, 2-yr., $5 / 8$ to $11-16$ in., strong grade...................... 60.00

In car lots..................................... 55.00

The lighter grades are all sold. Varieties as follows:

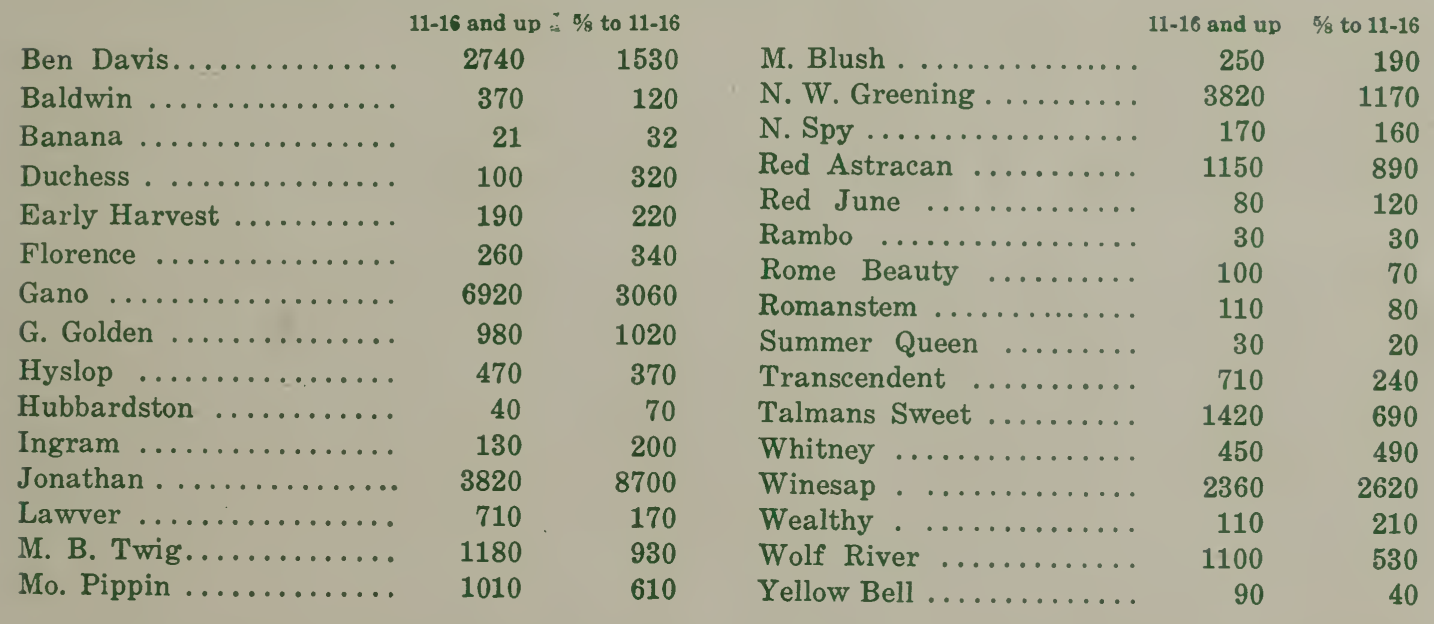

Trees packed in bulk at above prices. If boxed, a charge sufficient to cover actual cost will be added.

\section{F. W. WATSON \& CO., Topeka, Kansas}




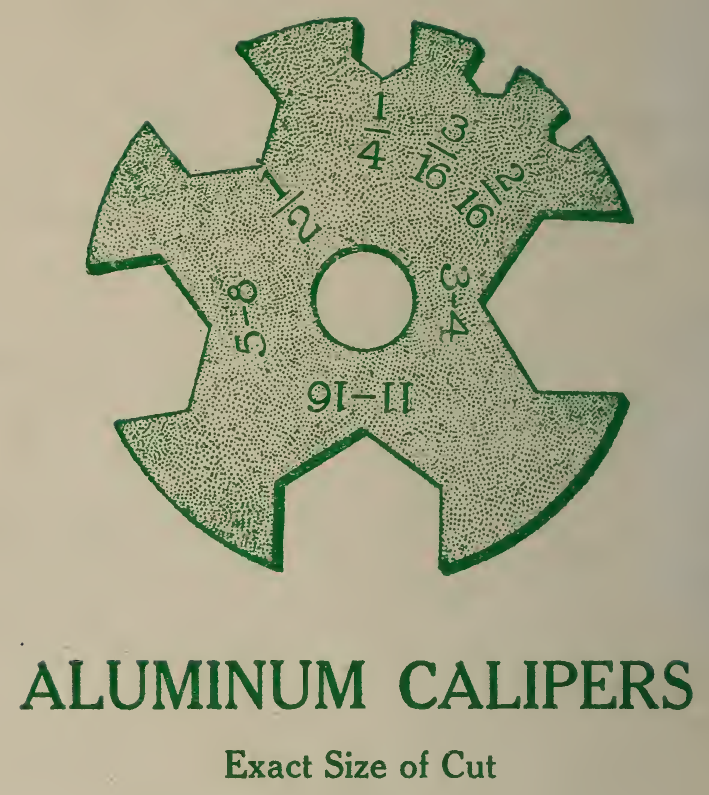

Each, postpaid, 25 cents

\section{F. W. WATSON \& CO. TOPEKA, KANSAS}

